\title{
The first pipizine hoverfly from the Oligocene of Céreste, France
}

Valentin Nidergas, Jiří Hadrava, Romain Garrouste, Jakub Prokop, Thomas Schubnel, and André Nel Acta Palaeontologica Polonica 63 (3), 2018: 539-548 doi:https://doi.org/10.4202/app.00500.2018

The Oligocene Oligopipiza quadriguttata Nidergras, Hadrava, and Nel gen et sp. nov. is the first fossil Pipizinae found in the lacustrine outcrop of Céreste (South-East of France). It differs from the other Pipizinae in the male genitalia, with a surstylus without tooth and shorter than epandrium, and a long epandrium with a very deep and narrow median theca. It is compared to other extant and fossil Pipizinae. Its position in this clade is supported by its inclusion in previous morphological phylogenetic analysis of the Syrphidae. Palaeoecological inferences for the paleobiota of Céreste are made based on this taxon and point to the presence of a mixed forest. The taphonomy of these flies is discussed. They were probably embedded in surface microbial mats. The pollinator role of Oligopipiza quadriguttata is also discussed on the basis of the presence of pollen surrounding the fossil flies.

Key words: Insecta, Syrphidae, Pipizinae, palaeoecology, Paleogene, France.

Valentin Nidergas [valentin.nidergas@gmail.com], Romain Garrouste [garroust@mnhn.fr

], Thomas Schubnel [thomas.schubnel@wanadoo.fr], and André Nel [anel@mnhn.fr ] (corresponding author), Institut Systématique Evolution Biodiversité (ISYEB), Muséum national d'Histoire naturelle, CNRS, Sorbonne Université, EPHE, 57 rue Cuvier, CP 50, F-75005 Paris, France. Jiří Hadrava [hadravaj@ natur.cuni.cz] and Jakub Prokop [jprokop@ @atur.cuni.cz], Department of Zoology, Faculty of Science, Charles University, Viničná 7, CZ-128 43, Praha 2, Czech Republic.

This is an open-access article distributed under the terms of the Creative Commons Attribution License (for details please see creativecommons.org), which permits unrestricted use, distribution, and reproduction in any medium, provided the original author and source are credited. 
Far Full text $(982.5 \mathrm{kB})$ ।

Far 5 Supplementary file $(237.0 \mathrm{kB})$ 